\title{
A prediction model of contrast-associated acute kidney injury in patients with hypoalbuminemia undergoing coronary angiography
}

Liwei Liu ${ }^{1,2+}$, Jin Liü ${ }^{2+}$, Li Lei ${ }^{1,2+}$, Bo Wang ${ }^{2+}$, Guoli Sun², Zhaodong Guo², Yibo He², Feier Song ${ }^{3}$, Zhubin Lun ${ }^{4}$, Bowen Liu', Guanzhong Chen ${ }^{5}$, Shiqun Chen ${ }^{2}$, Yongquan Yang ${ }^{2,5}$, Yong Liu ${ }^{1,2,5^{*}}$ (1) and Jiyan Chen ${ }^{1,2,5^{*}}$

\begin{abstract}
Background: Risk stratification is recommended as the key step to prevent contrast-associated acute kidney injury (CA-AKI) among at-risk patients following coronary angiography (CAG) and/or percutaneous coronary intervention $(\mathrm{PCI})$. Patients with hypoalbuminemia are prone to $\mathrm{CA}-\mathrm{AKI}$ and do not have their own risk stratification tool. Therefore, this study developed and validated a new model for predicting CA-AKI among hypoalbuminemia patients $\mathrm{CAG} / \mathrm{PCl}$.
\end{abstract}

Methods: 1272 patients with hypoalbuminemia receiving CAG/PCI were enrolled and randomly allocated (2:1 ratio) into the development cohort $(n=848)$ and the validation cohort $(n=424)$. CA-AKI was defined as an increase of $\geq 0.3 \mathrm{mg} / \mathrm{dL}$ or $50 \%$ in serum creatinine (SCr) compared to baseline in the 48 to $72 \mathrm{~h}$ after CAG/PCI. A prediction model was established with independent predictors according to stepwise logistic regression, showing as a nomogram. The discrimination of the new model was evaluated by the area under the curve (AUC) and was compared to the classic Mehran CA-AKI model. The Hosmer-Lemeshow test was conducted to assess the calibration of our model.

Results: Overall, 8.4\% (71/848) patients of the development group and 11.2\% (48/424) patients of the validation group experienced CA-AKI. A new nomogram included estimated glomerular filtration rate (eGFR), serum albumin (ALB), age and the use of intra-aortic balloon pump (IABP); showed better predictive ability than the Mehran score (C-index 0.756 vs. $0.693, p=0.02$ ); and had good calibration (Hosmer-Lemeshow test $p=0.187$ ).

Conclusions: We developed a simple model for predicting CA-AKI among patients with hypoalbuminemia undergoing $\mathrm{CAG} / \mathrm{PCl}$, but our findings need validating externally.

Trial registration: http://www.ClinicalTrials.gov NCT01400295, retrospectively registered 21 July 2011.

Keywords: Contrast-associated kidney injury, Hypoalbuminemia, Nomogram, Coronary angiography, Percutaneous coronary intervention

\footnotetext{
*Correspondence: liuyong2099@126.com; chenjiyandr@126.com

'Liwei Liu, Jin Liu, Li Lei and Bo Wang contributed equally to this work.

${ }^{1}$ The Second School of Clinical Medicine, Southern Medical University, Guangzhou 510515, Guangdong, China

Full list of author information is available at the end of the article
}

C C The Author(s). 2020 Open Access This article is licensed under a Creative Commons Attribution 4.0 International License, which permits use, sharing, adaptation, distribution and reproduction in any medium or format, as long as you give appropriate credit to the original author(s) and the source, provide a link to the Creative Commons licence, and indicate if changes were made. The images or other third party material in this article are included in the article's Creative Commons licence, unless indicated otherwise in a credit line to the material. If material is not included in the article's Creative Commons licence and your intended use is not permitted by statutory regulation or exceeds the permitted use, you will need to obtain permission directly from the copyright holder. To view a copy of this licence, visit http://creativecommons.org/licenses/by/4.0/. The Creative Commons Public Domain Dedication waiver (http://creativecommons.org/publicdomain/zero/1.0/) applies to the data made available in this article, unless otherwise stated in a credit line to the data. 


\section{Background}

Contrast-associated acute kidney injury (CA-AKI) is one of the major complications that occur after contrast exposure [1], leading to higher mortality and worse clinical outcomes [2]. The guidelines recommend that the risk of CA-AKI should be assessed among patients receiving contrast exposure [3].

Hypoalbuminemia is a frequent problem in patients with cardiovascular disease, with a prevalence ranging from 10 to $40 \%$ in coronary artery disease patients [4-7]. A previous study has reported that hypoalbuminemia is an independent risk factor for CA-AKI [8]. Elderly age, inflammation and comorbidities, considered as main factors in the occurrence of hypoalbuminemia [9], are also the important mechanism for developing CA-AKI. Moreover, the development of AKI is associated with worse survival than the absence of AKI in patients with baseline hypoalbuminemia [10].

Although patients with baseline hypoalbuminemia are more vulnerable to CA-AKI, there is no prediction model to identify such patients. A recent review concluded that only a few published models are available for routine clinical use [11]. Thus, this study intended to establish a new predicting model to assess the risk of CAAKI among patients with hypoalbuminemia following CAG or PCI.

\section{Methods}

\section{Patients}

From January 2010 to October 2012, this prospective study reviewed patients aged $\geq 18$ years with baseline hypoalbuminemia [hypoalbuminemia was defined as serum albumin less than $3.5 \mathrm{~g} / \mathrm{L} \quad(<35 \mathrm{mg} / \mathrm{dl})$ ] who were undergoing CAG or PCI and who were included in an observational cohort (PREdictive Value of COntrast voluMe to creatinine Clearance Ratio, PRECOMIN, NCT01400295) in Guangdong Provincial People's Hospital [12, 13]. The criteria of exclusion included lactation, intravascular injection of contrast agents within the 7 days before or 3 days after operation, no use of isotonic saline for hydration, no use of low-osmolarity contrast medium, cardio surgery or endovascular repair therapy, end-stage kidney disease or renal replacement therapy, malignancy, pregnancy, missing data of perioperative creatinine [12]. All patients of our cohort signed informed consent.

Finally, 1272 patients with baseline hypoalbuminemia $(<35 \mathrm{mg} / \mathrm{dl})$ were enrolled in the analysis. All eligible patients were randomly divided (2:1 ratio) into 2 group: development cohort $(n=848)$ and validation cohort $(n=424)$. During the median follow-up time of 7.7 $(6.8 ; 8.8)$ years, the event(all-cause mortality) was recorded by experienced nurses via telephone visits.

\section{Coronary angiography and percutaneous coronary intervention}

Patients suspected of or diagnosed of coronary artery disease were undergoing CAG/PCI. During the operation, standard guidewires, catheters, and stents and the dose of contrast were used and determined by the interventional cardiologist. All procedures were performed according to the guidelines of the American Heart Association/American College of Cardiology Foundation [14].

Based on the guildline [15], each patient received intravenous hydration of isotonic saline with a rate of 1 $\mathrm{mL} / \mathrm{kg}$ per hour for at least 2 to $12 \mathrm{~h}$ before and 6 to 24 $\mathrm{h}$ after the CAG/PCI, while $0.5 \mathrm{~mL} / \mathrm{kg}$ per hour in cases of severe congestive heart failure or left ventricular ejection fraction (LVEF) $<40 \%$.

\section{Study endpoint and definitions}

The endpoint in this study was CA-AKI defined as an increase of $\geq 0.3 \mathrm{mg} / \mathrm{dL}$ or $50 \%$ in serum creatinine $(\mathrm{SCr}$ ) compared to baseline in the 48 to $72 \mathrm{~h}$ after CAG/PCI [16]. The definition of CKD was as an estimated glomerular filtration rate $(\mathrm{eGFR})<60 \mathrm{~mL} / \mathrm{min} / 1.73 \mathrm{~m}^{2}$, which was calculated by the Modification of Diet in Renal Disease (MDRD) formula. The definitions of hypotension, diabetes, IABP, and CHF were the same as those used in the Mehran score [17]. Serum albumin (ALB) was analyzed by an automatic biochemical analyzer (Beckman Coulter AU5800, Ireland). The Mehran scores included eight variables (age $>75$ years, hypotension, IABP, CKD, $\mathrm{CHF}$, diabetes, anemia and contrast volume) [17], and the score of each patient was calculated by trained clinicians. Experienced nurses recorded follow-up of mortality via telephone visits every year after enrollment till April 2019.

\section{Statistical analysis}

Comparisons between normally distributed continuous variables were performed using t-tests, expressed as the mean \pm SD. While nonnormally distributed variables were examined via the Wilcoxon rank-sum test, presented as the median \pm interquartile. The Pearson $\chi^{2}$ or Fisher exact tests were used for categorical data, shown as percentages. Kaplan-Meier curves were plotted to explore the relationship between CA-AKI and all-cause death among patients with or without hypoalbuminemia. The impact of CA-AKI on long-term mortality among patients with or without hypoalbuminemia was assessed using multivariate Cox regression [18, 19].

The associations between CA-AKI and variables in the development cohort were assessed by univariable logistic analysis. Collinearity between variables was evaluated. Variables were included in the multivariable analysis using a cut-off of $P<0.05$ in univariate logistics regression. Backward stepwise regression was conducted to 
select factors and develop our final model, showing as a nomogram. The regression coefficient of each variable in the model was transformed into a 0 to 100 point scale. The total points were calculated by adding points of each variable and then turned into predicted probabilities. A receiver operating characteristic (ROC) curve and AUC were used to assess the discrimination of the nomogram in both the development and validation cohorts compared to the Mehran score. Internal validation was analyzed using 1000 bootstrap samples [13, 20]. The Hosmer-Lemeshow test and a calibration curve were used to assess the calibration of our model. Variables with missing values $>15 \%$ were not considered candidates. All statistical analyses were analyzed in SPSS software (ver. 25.0) and R software (ver. 3.6.2).

\section{Results}

\section{Baseline clinical characteristics}

During this study period, 1272 consecutive patients who had baseline hypoalbuminemia were enrolled. The incidence of CA-AKI was 9.36\% (119/1272). Patients with baseline hypoalbuminemia were elderly (mean age: $66.00 \pm 10.63$ years) and having many comorbidities, such as CKD (28\%), acute myocardial infarction (AMI) $(45.8 \%)$, anemia $(41.8 \%)$. The incidence of CA-AKI in the development cohort was $8.4 \%(71 / 848)$, and in the validation cohort was $11.2 \%(48 / 424)$. No significant difference was identified between these two cohorts, except for in hydration volume (Table 1). More contrast volume was used in patients undergoing PCI, but no statistical difference was shown in the prevalence of CA-AKI (Supplementary Table 1).

Patients with CA-AKI tended to have lower eGFR, LVEF, ALB and higher age, heart rate (HR), and SCR in the development cohort (Supplementary Table 2). At baseline, CA-AKI patients had more complications, such as CKD, CHF, AMI, hypertension, and anemia.

\section{Development and validation}

The results of univariate logistic analysis about associations with CA-AKI are shown in Table 2. After multivariate stepwise selection, IABP (OR: 8.267, 95\% CI: 4.007-16.978), eGFR (OR: 0.982, 95\% CI: 0.970-0.994) and ALB (OR: $0.875,95 \%$ CI: 0.801-0.955), age (OR: 1.036, 95\% CI: $1.006-1.007)$ were included in the final model for predicting CA-AKI (Table 3).

Based on these independent risk factors, a simple nomogram was formed (Fig. 1). In the development cohort, the nomogram displayed good discriminative power of predicting the CA-AKI (AUC 0.816, 95\% CI: 0.763-0.862; bootstrap corrected C-index 0.802). Compared to the Mehran score, this nomogram had good discrimination (AUC 0.816 VS 0.775, shown in Fig. 2). Besides, calibration plots graphically presented great
Table 1 Baseline characteristics of the development cohort and validation cohort

\begin{tabular}{llll}
\hline & $\begin{array}{l}\text { Development } \\
(n=844)\end{array}$ & $\begin{array}{l}\text { Validation } \\
(n=428)\end{array}$ & $\mathrm{p}$ \\
\hline Age, y & $66.02(10.44)$ & $65.96(11.02)$ & 0.921 \\
Female, $\mathrm{n}(\%)$ & $204(24.2)$ & $82(19.2)$ & 0.051 \\
Weight, $\mathrm{n}$ & $63.48(10.10)$ & $62.62(10.49)$ & 0.361 \\
SBP, $\mathrm{mmHg}$ & $127.66(20.48)$ & $128.85(20.78)$ & 0.329 \\
DBP, $\mathrm{mmHg}$ & $74.30(12.08)$ & $74.92(12.31)$ & 0.385 \\
HR, bpm & $75.61(13.73)$ & $75.60(14.41)$ & 0.989
\end{tabular}

\section{Medical history}

AMI, n (\%)

$251(29.7)$

$105(24.5)$

0.059

$378(45.1)$

$202(47.3)$

0.495

Hypertension, $\mathrm{n}(\%)$

$494(58.5)$

Pre-hypotension, n (\%)

$13(1.5)$

$250(58.5)$

1

Hyperlipidemia, n (\%)

$99(11.7)$

$9(2.1)$

0.621

Anemia, n (\%)

$346(41.6)$

$40(9.3)$

0.233

$\mathrm{DM}, \mathrm{n}(\%)$

219 (25.9)

$179(42.2)$

0.878

CHF, n (\%)

198 (23.6)

$96(22.5)$

0.2

LVEF, n

56.28 (12.98)

87 (20.4)

0.227

NYHA

$1.92(0.76)$

$55.39(12.16)$

0.262

\section{Laboratory examination}

eGFR, $\mathrm{mL} / \mathrm{min} / 1.73 \mathrm{~m}^{2}$

$\mathrm{Scr}, \mu \mathrm{mol} / \mathrm{L}$

$72.30(22.57)$

$73.42(21.68) \quad 0.395$

ALB, $g / l$

$\mathrm{Lpa}, \mathrm{mg} / \mathrm{dl}$

103.03 (59.22)

100.22 (40.16)

0.379

BUN, mg/dl

$31.59(2.72)$

$31.60(2.74)$

0.96

$\mathrm{Na}, \mathrm{mmol} / \mathrm{L}$

$.55(36.49)$

$34.10(38.28)$

0.849

$5.61(3.03)$

5.67 (3.02)

0.75

$\mathrm{K}, \mathrm{mmol} / \mathrm{L}$

$138.82(3.40)$

$138.42(3.43)$

0.097

Medications

Metformin, n (\%)

$31(3.7)$

ACEI/ARB, n (\%)

735 (87.1)

$16(3.7)$

$187(22.2)$

388 (90.7)

0.075

Diuretics, n (\%)

$678(80.3)$

97 (22.6)

0.603

Beta blocker, n (\%)

$362(84.6)$

0.076

\section{Procedure}

Contrast volume, $\mathrm{mL}$

IABP, n (\%)

Hydration volume, $\mathrm{mL}$

\subsection{9 (66.22)}

131.97 (63.40)

0.603

\section{Other}

CA-AKI, n (\%)

$43(5.1)$

$18(4.2)$

0.574

874.12 (516.30)

816.60 (418.54)

0.047

Mehran score

$71(8.4)$

48 (11.2)

0.129

Abbreviations: CA-AKI Contrast-associated acute kidney injury, SBP Systolic blood pressure, DBP Diastolic blood pressure, HR Heart rate, CKD Chronic kidney disease, $A M I$ Acute myocardial infarction, DM Diabetes mellitus, CHF Congestive heart failure, LVEF Left ventricular ejection fraction, NYHA NYHA classification grading of cardiac function, eGFR Estimated glomerular filtration rate, ALB Serum albumin, Lpa Lipoprotein a, BUN Blood urea nitrogen, IABP Intra-aortic balloon pump, Scr Serum creatinine 
Table 2 Univariate logistic regression

\begin{tabular}{llll}
\hline & OR & $95 \% \mathrm{Cl}$ & $\mathrm{P}$ \\
\hline ALB & 0.817 & $0.756-0.883$ & $<0.001$ \\
Contrast volume & 1.003 & $0.999-1.006$ & 0.136 \\
DM & 1.514 & $0.889-2.517$ & 0.117 \\
Pre-hypotension & 3.459 & $0.762-11.633$ & 0.064 \\
PCI & 1.387 & $0.804-2.512$ & 0.257 \\
eGFR & 0.968 & $0.957-0.979$ & $<0.001$ \\
Scr & 1.006 & $1.003-1.010$ & $<0.001$ \\
Age & 1.058 & $1.030-1.088$ & $<0.001$ \\
AMI & 2.113 & $1.290-3.520$ & 0.003 \\
NYHA & 2.290 & $1.587-3.308$ & $<0.001$ \\
CKD & 3.664 & $2.237-6.066$ & $<0.001$ \\
Hypertension & 2.404 & $1.397-4.342$ & 0.002 \\
IABP & 12.788 & $6.558-24.868$ & $<0.001$ \\
CHF & 3.848 & $2.34-6.338$ & $<0.001$ \\
LVEF & 0.966 & $0.949-0.984$ & $<0.001$ \\
HR & 1.018 & $1.005-1.031$ & 0.005 \\
Anemia & 1.802 & $1.106-2.956$ & $<0.001$ \\
BUN & 1.131 & $1.067-1.197$ & $<0.001$ \\
Diuretics & 1.658 & $1.084-2.465$ & 0.015 \\
Beta-blocker & 0.510 & $0.302-0.885$ & 0.014 \\
Hydration volume & 1.001 & $1.000-1.001$ & $<0.001$ \\
\hline Abbrevatons: CAN Cont & & \\
\hline
\end{tabular}

Abbreviations: CA-AKI Contrast-associated acute kidney injury, eGFR Estimated glomerular filtration rate, $A M I$ Acute myocardial infarction, IABP Intra-aortic balloon pump, CHF Congestive heart failure, LVEF Left ventricular ejection fraction, $H R$ Heart rate, $A L B$ Serum albumin, $B U N$ Blood urea nitrogen; infarction, Scr Serum creatinine, $P C I$ Percutaneous coronary intervention

agreement regarding the development of CA-AKI between the risk assessment and the observed frequency (Fig. 3). The Hosmer-Lemeshow statistic suggested a good fit $\left(\chi^{2}=3.65, P=0.887\right)$ in the development cohort.

In the validation group, the new nomogram demonstrated a C-index of 0.756 (95\% CI $0.685-0.832$ ), showing better discriminative power than Mehran score (AUC: $0.693,95 \%$ CI $0.608-0.779)$ among patients $(P=$ 0.02, Fig. 4). Besides, our model had a good performance of calibration in the validation cohort $\left(x^{2}=11.27, P=\right.$ 0.187 , Fig. 3). The clinical usefulness of the new nomogram was better than Mehran score in the development and validation cohort (Supplementary figure 1A and B).

Table 3 Multivariate logistic regression

\begin{tabular}{llll}
\hline & OR & $95 \% \mathrm{Cl}$ & $\mathrm{p}$ \\
\hline eGFR & 0.982 & $0.970-0.994$ & 0.004 \\
ALB & 0.875 & $0.801-0.955$ & 0.002 \\
IABP & 8.267 & $4.007-16.978$ & $<0.001$ \\
Age & 1.036 & $1.006-1.067$ & 0.018 \\
\hline
\end{tabular}

Abbreviations: eGFR Estimated glomerular filtration rate, ALB Serum albumin, $I A B P$ Intra-aortic balloon pump

\section{Follow-up of clinical outcomes}

We divided patients into 2 groups according to whether they developed CA-AKI. During the follow-up time, the rates of mortality were 30.2 and $17.1 \%$ in the CA-AKI group and non-CA-AKI group, respectively. According to the log-rank analysis (Fig. 5), the occurrence of CAAKI presented higher long-term mortality $(P<0.01)$ in patients with hypoalbuminemia. By multivariate Cox regression analysis, CA-AKI was an independent prognostic risk factor in patients with hypoalbuminemia (Hazard ratio:1.525, 95\% CI 1.03-2.25) after adjusting for diabetes, age, gender, hypertension, IABP and eGFR (Supplementary Table 3). Similarly, among patients with normal albumin levels, the occurrence of CA-AKI presented worse prognosis (Log-rank analysis $P<0.01$, Supplementary Figure 2). CA-AKI was independently associated with the long-term mortality (Hazard ratio: $1.489,95 \%$ CI 1.013-2.187) in a prognostic model (Supplementary Table 3$)$.

\section{Discussion}

Our study was the first to develop a CA-AKI risk stratification model in a population with hypoalbuminemia. We established a simple nomogram that included four powerful predictors for clinical use (IABP, ALB, eGFR, age). Compared to the classical Mehran score, the new model had good discrimination and calibration in predicting CA-AKI.

Hypoalbuminemia is associated with several pathological conditions. Yu et al. [10] showed that hypoalbuminemia often was observed in elderly patients and in patients having many comorbidities. Similarly, in our cohort, most patients were older and accompanying CKD, AMI, anemia and CHF, which may lead to the status of low serum albumin level. The overall incidence of CAAKI was $9.36 \%$ in this study, which was relatively high but similar to the high-risk population, such as patients with CKD or AMI [21, 22]. Several studies have demonstrated that hypoalbuminemia is an independent risk factor for CA-AKI [8] and is closely related to poor prognosis in coronary heart disease [23]. Yu et al. [10] reported that patients with hypoalbuminemia had a high incidence of AKI in the hospital. Furthermore, in our study, the development of AKI in patients was associated with a long-term mortality according to the results of the 7-year follow-up, which was similar to a previous study [10]. Due to the poor prognosis of CA-AKI in patients with known hypoalbuminemia, it is necessary for clinicians to early identify the high-risk individual of CA-AKI, leading to prompt management and intervention.

Risk assessment in high-risk groups is a primary aim and important for the prevention of CA-AKI, so a large number of models have been proposed [11]. Although 


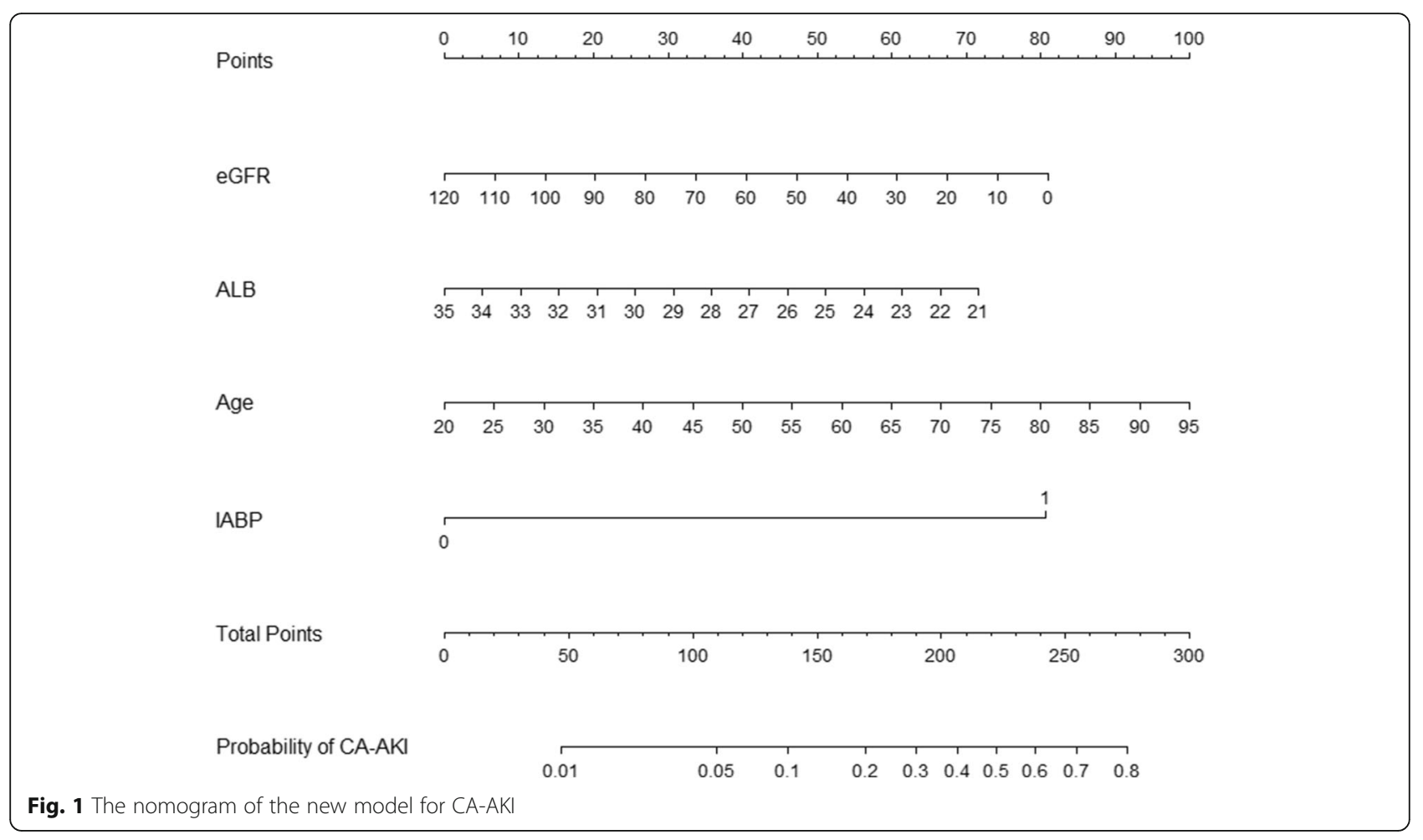

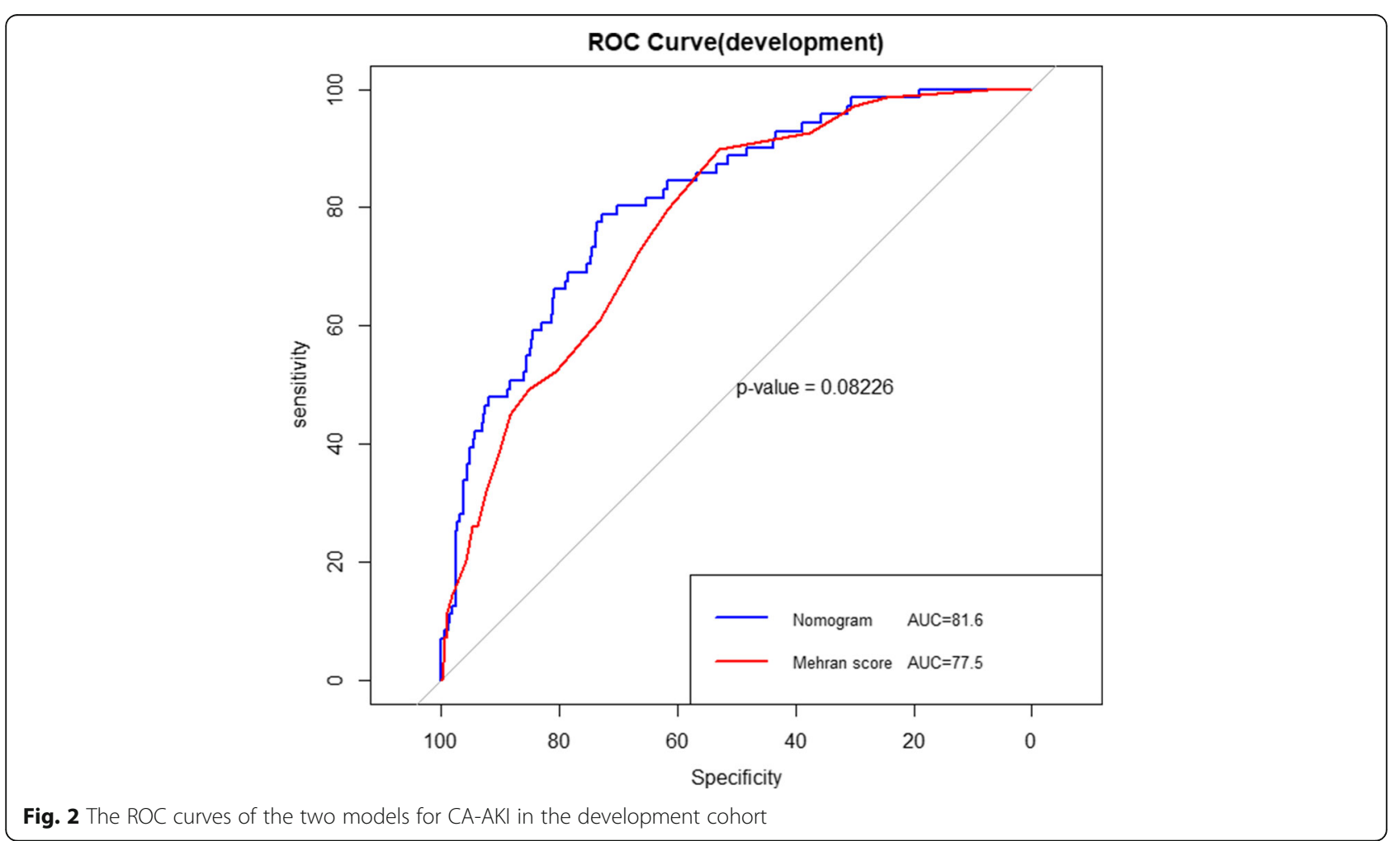




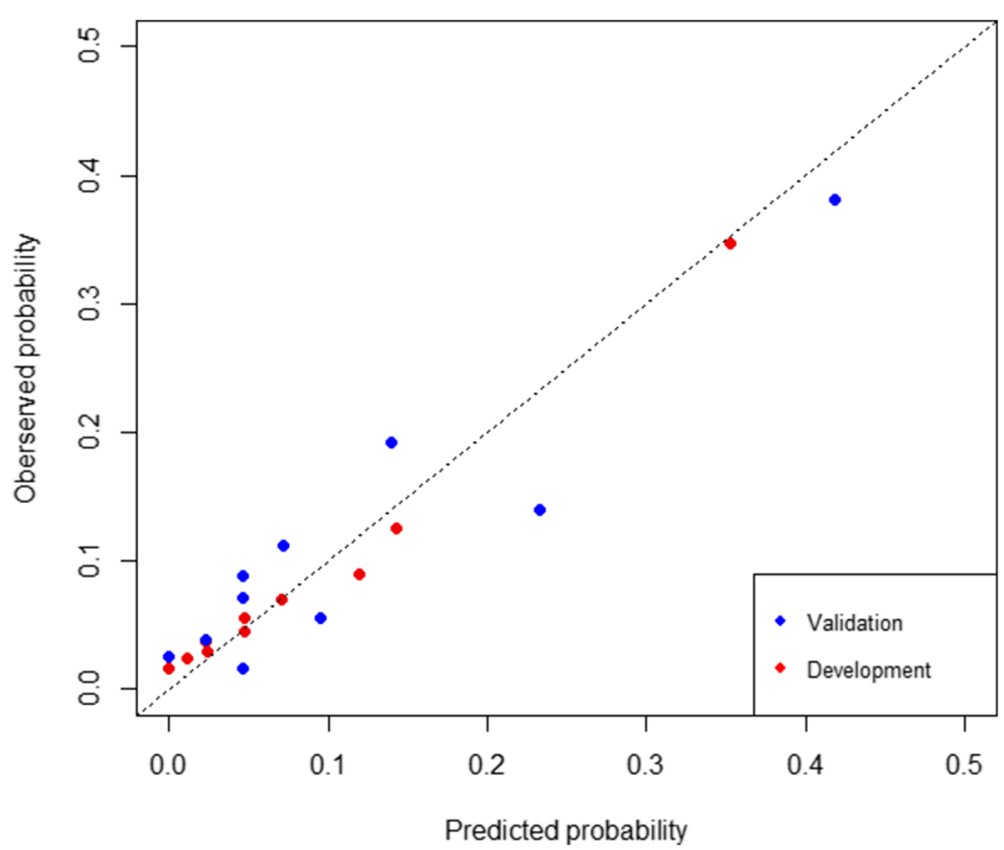

Fig. 3 The calibration curve of the new model in the development cohort and validation cohort

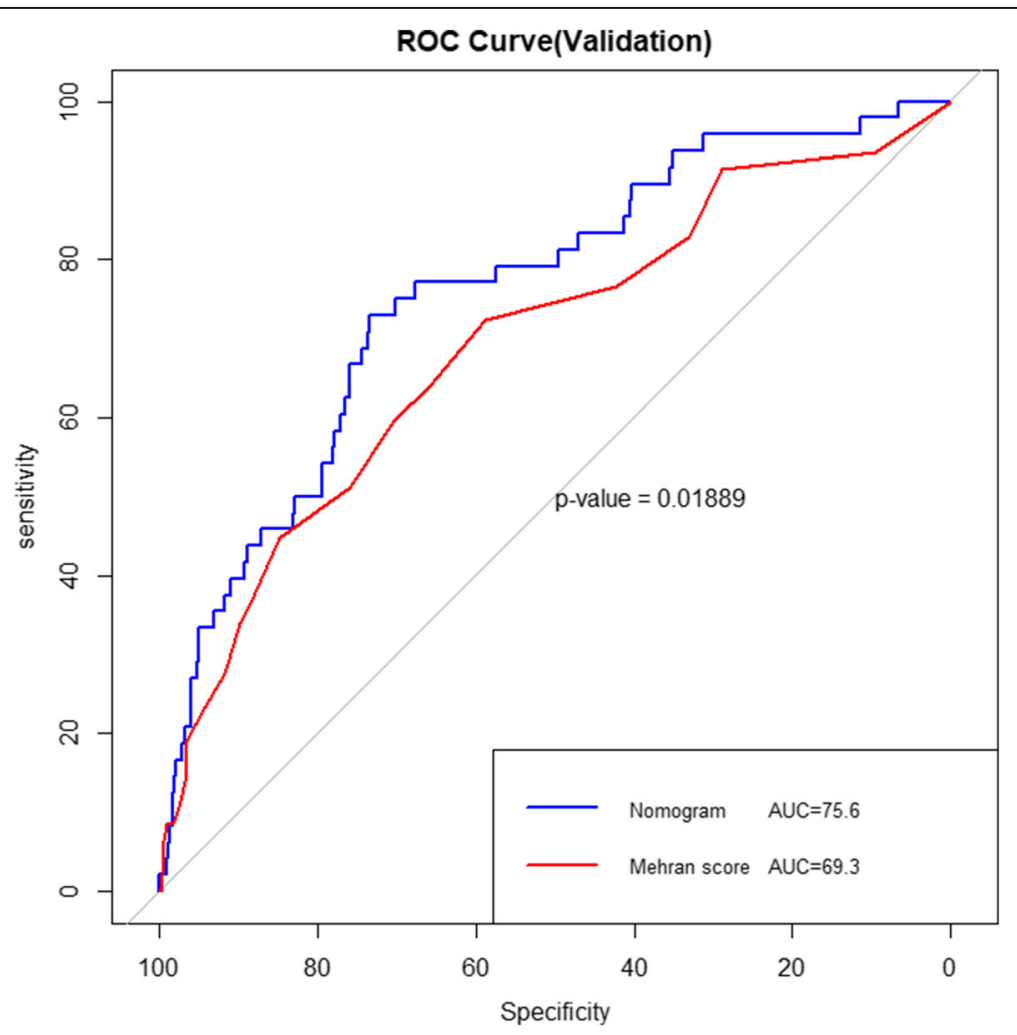

Fig. 4 The ROC curves of the two models for CA-AKI in the validation cohort 


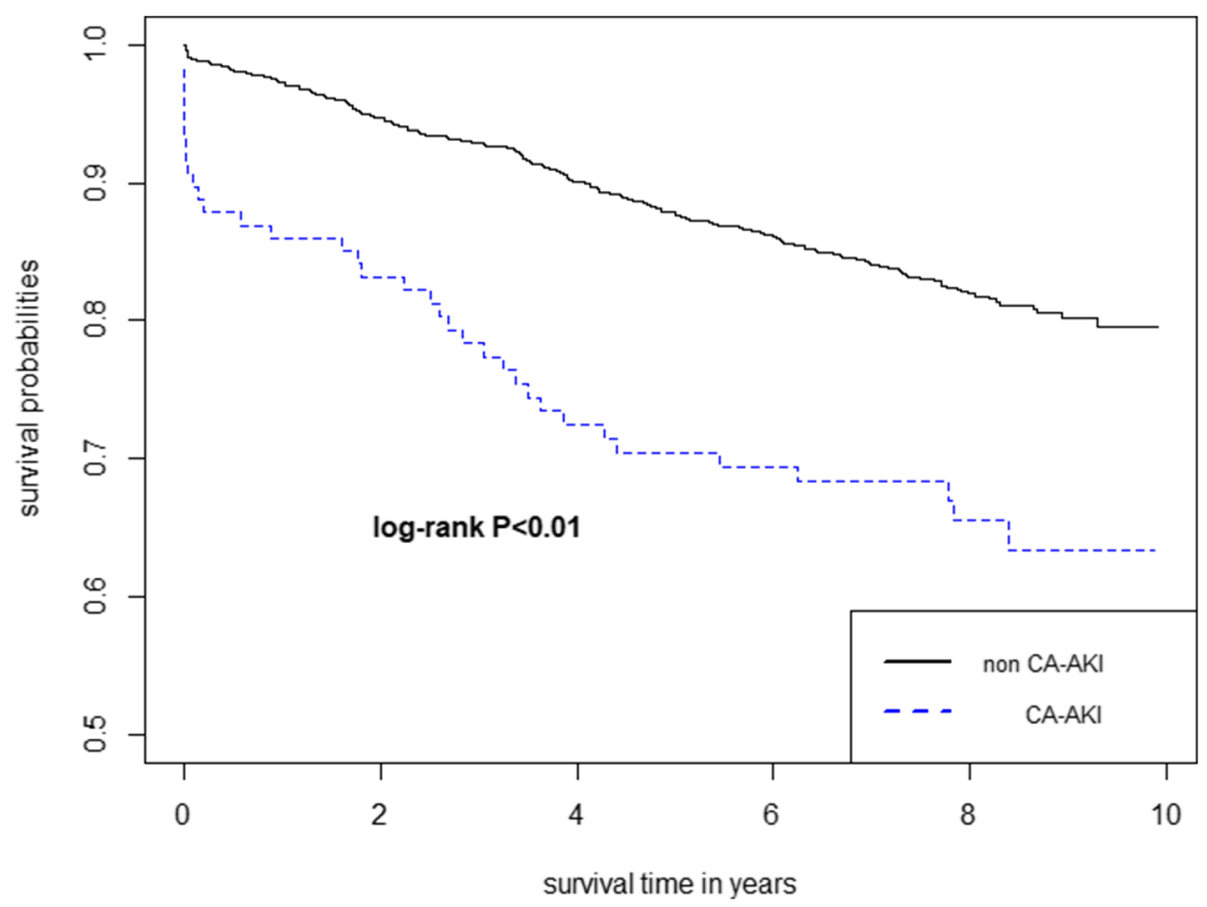

Fig. 5 The Kaplan-Meier curve to estimates the impact of CA-AKI on long-term mortality in patients with hypoalbuminemia

the classic Mehran score or other models had good predictive efficiency, most models included 5-8 variables, and some factors required the subjective judgment of clinicians. In recent years, predictive models have been established for different populations at high risk of CAAKI, such as patients with CKD [24], AMI [25] or diabetes mellitus [26]. However, there was no predictive model for patients with hypoalbuminemia. Because of the high incidence of CA-AKI in patients with hypoalbuminemia, it is essential to develop a simple risk score for these patients undergoing CAG/PCI.

For predicting CA-AKI, the currently available models seldom included albumin [11] because serum albumin was a novel laboratory risk factor. Murat et al. [8] suggested that albumin is an independent and good predictor of CA-AKI among patients with ACS undergoing PCI. Low serum albumin concentrations reflect the inflammatory state of the body, which may lead to CAAKI [9].

The use of IABP was the strongest predictor of CAAKI in the present model. Previous studies reported that IABP reflected the unstable hemodynamics and was independently associated with CA-AKI $[24,27]$. Bartholomew et al. [28] firstly showed a close relationship between the use of IABP and CA-AKI, and then Mehran et al. [17] first included IABP in a model of CA-AKI prediction. Perioperative hemodynamic abnormalities may result in ischemia-reperfusion injury, which could lead to a potential impact on the AKI.
Currently, age was an independent predicting variable of the occurrence of CA-AKI in the known risk model $[17,29]$. This independent predictive ability may be related to a degenerative change in the structure and function of kidneys with increasing age. Baseline eGFR was also a common risk factor for CA-AKI following CAG [30]. eGFR represents worse kidney function and a higher risk of acute kidney injury [31].

Diabetes and contrast volume were not included in our nomogram, although these variables were included in previous models [32]. In our study, diabetes and contrast volume were not independent risk factors for CAAKI based on statistical analysis. Similar to our finding, Sabeti et al. [33] showed that diabetes mellitus was not an independent risk factor for CA-AKI. A recent review concluded that diabetes is not independently associated with the risk of developing CA-AKI and only increases susceptibility in patients with underlying kidney dysfunction [34]. Current studies hold that the comorbidities and hemodynamic instability were more related to the occurrence of AKI after contrast exposure rather than high volume of contrast [35, 36]. In our cohort, the association between contrast volume and CA-AKI showed no statistically significant difference. One of possible reasons for this result is that hypoalbuminemia patients tend to have more comorbidities and unstable hemodynamics [10]. As for anemia and LVEF, these factors were associated with CA-AKI in univariable, but not in multivariable analysis, which was similar to other 
studies [11,37]. Our results suggested that the impact of anemia on CA-AKI may be potentially affected by confounding factors, like renal dysfunction or age. Similarly, Gao et al. showed the LVEF was not independently related to CA-AKI when adjusting for age or IABP [38]. The KDIGO guidelines [39] suggest that eGFR should be used instead of Scr to assess baseline renal function in patients before the administration of contrast medium because Scr is also affected by age, gender, and race. Hydration has been considered an effective treatment for CA-AKI, but the actual effect of this strategy is still controversial. Perioperative hydration can expand plasma volume by inhibiting the renin-angiotensin-aldosterone system, reducing the concentration of contrast media in the tubule lumen and vasa recta, and counteraction of medullary vasoconstriction activation [40].. It is still the cornerstone of CA-AKI prevention. But, the rate and duration of hydration remain inconsistent. Meanwhile, the AMACING trial challenged the tenet that intravenous fluids are effective. The incidence of CA-AKI between the hydration group and the non-hydration group (2.7\% vs $2.6 \%)$ showed no statistical significant difference [41]. In our study, the volume of hydration was not significantly different in multivariate regression, so this variable was not included in our model. By using our nomogram, clinicians can identify high-risk patients with CA-AKI early and treat them in a timely manner.

\section{Limitations}

Firstly, the data of our study were from a single-center hospital. But this cohort was a large database about CAAKI in China focusing on patients with hypoalbuminemia.

Secondly, our model is not as effective as other models, but it has fewer objective variables and higher clinical operability. Importantly, our model has good predictive and evaluative effectiveness in hypoalbuminemia populations.

Thirdly, the nomogram established has not been externally verified. However, we randomly divided all the patients into a development group and a validation group according to a 2:1 ratio, which showed that our model had good stability.

Finally, our study lacked data of creatinine after 3 days because several patients were discharged on the third day after CAG/PCI. This may affect the incidence of CA-AKI.

\section{Supplementary information}

Supplementary information accompanies this paper at https://doi.org/10. 1186/s12872-020-01689-6.

Additional file 1: Table S1. Baseline characteristics of non-PCl group and $\mathrm{PCl}$ group in total cohort. Table S2. Baseline characteristics of CAAKI group and non CA-AKI group in developing cohort. Table S3.
Multivariate Cox regression analysis of risk factors for long-term mortality. Table S4. Multivariate logistic regression of variates with statistically significant difference in univariate analysis.

Additional file 2: Figure S1. Decision curve analysis for the development cohort (A) and the validation cohort (B).

Additional file 3: Figure S2. Association between CA-AKI and longterm mortality in patients without hypoalbuminemia.

\begin{abstract}
Abbreviations
CA-AKI: Contrast-associated acute kidney injury; DBP: Diastolic blood pressure; SBP: Systolic blood pressure; CKD: Chronic kidney disease; HR: Heart rate; AMI: Acute myocardial infarction; DM: Diabetes mellitus; NYHA: NYHA classification grading of cardiac function; eGFR: Estimated glomerular filtration rate; CHF: Congestive heart failure; LVEF: Left ventricular ejection fraction; IABP: Intra-aortic balloon pump; ALB: Serum albumin; BUN: Blood urea nitrogen; Scr: Serum creatinine
\end{abstract}

\section{Acknowledgements}

None.

\section{Authors' contributions}

Substantial contributions to the conception and design of the study ( $L W L$, $J \mathrm{~L}, \mathrm{LL}, \mathrm{BW}$ ); data collection (GS, ZG, YH, FS, ZL, GC, BL); data analysis and/or interpretation of data for the work (SC, YY, YL, JYC); drafting of the work or revising it critically for important intellectual content $(L W L, L L, J L, Y L, J Y C$ ); final approval of the version to be published (all the authors)

\section{Authors' information}

Jiyan Chen takes responsibility for all aspects of the reliability and freedom from bias of the data presented and their discussed interpretation.

\section{Funding}

This work was supported by the Beijing Lisheng Cardiovascular Pilot Foundation [grant no. LHJJ201612127] and the National Science Foundation of China (grant no. 81670339). The funding body did not participate in the design of the study; the collection, analysis, and interpretation of the data; or in the writing of the manuscript.

Availability of data and materials

Data relevant to this study are available from the corresponding authors upon reasonable request.

Ethics approval and consent to participate

The study was approved by the Ethics Committee of Guangdong Provincial People's Hospital. All the patients enrolled in the study signed written informed consent

Consent for publication

Not applicable.

Competing interests

All authors declare that they have no competing interests.

\section{Author details}

${ }^{1}$ The Second School of Clinical Medicine, Southern Medical University, Guangzhou 510515, Guangdong, China. Department of Cardiology, Guangdong Provincial Key Laboratory of Coronary Heart Disease Prevention, Guangdong Cardiovascular Institute, Guangdong Provincial People's Hospital, Guangdong Academy of Medical Sciences, Guangzhou 510080, China. ${ }^{3}$ Department of Emergency and Critical Care Medicine, Guangdong Provincial People's Hospital and Guangdong Academy of Medical Sciences, Guangzhou 510080, People's Republic of China. ${ }^{4}$ Department of Cardiology, Dongguan People's Hospital, Dongguan 523059, China. ${ }^{5}$ Guangdong Provincial People's Hospital, School of Medicine, South China University of Technology, Guangzhou 510100, China. 
Received: 6 June 2020 Accepted: 26 August 2020

\section{Published online: 31 August 2020}

\section{References}

1. Mehran R, Dangas GD, Weisbord SD. Contrast-associated acute kidney injury. N Engl J Med. 2019;380:2146-55.

2. Sun G, Chen P, Wang K, Li H, Chen S, Liu J, et al. Contrast-induced nephropathy and long-term mortality after percutaneous coronary intervention in patients with acute myocardial infarction. Angiology. 2019; 70:621-6.

3. Neumann FJ, Sousa-Uva M, Ahlsson A, Alfonso F, Banning AP, Benedetto U, et al. 2018 ESC/EACTS Guidelines on myocardial revascularization. Eur Heart J. 2019;40:87-165

4. Brown JR, Mackenzie TA, Maddox TM, Fly J, Tsai TT, Plomondon ME, et al. Acute kidney injury risk prediction in patients undergoing coronary angiography in a national veterans health administration cohort with external validation. J Am Heart Assoc. 2015;4:e002136.

5. González-Pacheco H, Amezcua-Guerra LM, Sandoval J, Martínez-Sánchez C, Ortiz-León XA, Peña-Cabral MA, et al. Prognostic implications of serum albumin levels in patients with acute coronary syndromes. Am J Cardiol. 2017;119:951-8.

6. Justor B, Raquel D, Caroline D, Therese DP, Muteba M, Graham P, et al. Risk factors and outcomes of contrast-induced nephropathy in hospitalised south Africans. S Afr Med J. 2016;106:699-703.

7. Oduncu V, Erkol A, Karabay CY, Kurt M, Akgun T, Bulut M, et al. The prognostic value of serum albumin levels on admission in patients with acute ST-segment elevation myocardial infarction undergoing a primary percutaneous coronary intervention. Coron Artery Dis. 2013;24:88-94.

8. Murat SN, Kurtul A, Yarlioglues M. Impact of serum albumin levels on contrast-induced acute kidney injury in patients with acute coronary syndromes treated with percutaneous coronary intervention. Angiology. 2015;66:732-7

9. Soeters PB, Wolfe RR, Shenkin A. Hypoalbuminemia: pathogenesis and clinical significance. JPEN J Parenter Enteral Nutr. 2019;43:181-93.

10. Yu MY, Lee SW, Baek SH, Na KY, Chae DW, Chin HJ, et al. Hypoalbuminemia at admission predicts the development of acute kidney injury in hospitalized patients: a retrospective cohort study. PLoS One. 2017;12: e0180750.

11. Silver SA, Shah PM, Chertow GM, Harel S, Wald R, Harel Z. Risk prediction models for contrast induced nephropathy: systematic review. BMJ. 2015;351: h4395.

12. Liu Y, Chen JY, Tan N, Zhou YL, Yu DQ, Chen ZJ, et al. Safe limits of contrast vary with hydration volume for prevention of contrast-induced nephropathy after coronary angiography among patients with a relatively low risk of contrast-induced nephropathy. Circ Cardiovasc Interv. 2015;8: e001859.

13. Lei L, Xue Y, Guo Z, Liu B, He Y, Liu J, et al. Nomogram for contrast-induced acute kidney injury in patients with chronic kidney disease undergoing coronary angiography in China: a cohort study. BMJ Open. 2020;10:e037256.

14. Wright R, Anderson J, Adams C, Bridges C, Casey D, Ettinger S, et al. 2011 ACCF/AHA focused update of the Guidelines for the Management of Patients with Unstable Angina/Non-ST-Elevation Myocardial Infarction (updating the 2007 guideline): a report of the American College of Cardiology Foundation/American Heart Association Task Force on Practice Guidelines developed in collaboration with the American College of Emergency Physicians, Society for Cardiovascular Angiography and Interventions, and Society of Thoracic Surgeons. J Am College Cardiol. 2011; 57:1920-59.

15. Stacul F, van der Molen A, Reimer P, Webb J, Thomsen H, Morcos S, et al. Contrast induced nephropathy: updated ESUR contrast media safety committee guidelines. Eur Radiol. 2011;21:2527-41.

16. Tsai TT, Patel UD, Chang TI, Kennedy KF, Masoudi FA, Matheny ME, et al. Contemporary incidence, predictors, and outcomes of acute kidney injury in patients undergoing percutaneous coronary interventions: insights from the NCDR Cath-PCI registry. JACC Cardiovasc Interv. 2014;7:1-9.

17. Mehran R, Aymong ED, Nikolsky E, Lasic Z, lakovou I, Fahy M, et al. A simple risk score for prediction of contrast-induced nephropathy after percutaneous coronary intervention: development and initial validation. J Am Coll Cardiol. 2004;44:1393-9.

18. Roe MT, Chen AY, Thomas L, Wang TY, Alexander KP, Hammill BG, et al. Predicting long-term mortality in older patients after non-ST-segment elevation myocardial infarction: the CRUSADE long-term mortality model and risk score. Am Heart J. 2011;162:875-83.e1.

19. Tang EW, Wong CK, Herbison P. Global registry of acute coronary events (GRACE) hospital discharge risk score accurately predicts long-term mortality post acute coronary syndrome. Am Heart J. 2007;153:29-35.

20. Steyerberg EW, Vergouwe Y. Towards better clinical prediction models: seven steps for development and an ABCD for validation. Eur Heart J. 2014; 35:1925-31.

21. Nakahashi H, Kosuge M, Sakamaki K, Kiyokuni M, Ebina T, Hibi K, et al. Combined impact of chronic kidney disease and contrast-induced nephropathy on long-term outcomes in patients with ST-segment elevation acute myocardial infarction who undergo primary percutaneous coronary intervention. Heart Vessel. 2017;32:22-9.

22. Kuji S, Kosuge M, Kimura K, Nakao K, Ozaki Y, Ako J, et al. Impact of acute kidney injury on in-hospital outcomes of patients with acute myocardial infarction- results from the japanese registry of acute myocardial infarction diagnosed by universal definition (J-MINUET) substudy. Circ J. 2017;81:7339.

23. Shaper AG, Wannamethee SG, Whincup PH. Serum albumin and risk of stroke, coronary heart disease, and mortality: the role of cigarette smoking. Clin Epidemiol. 2004:57:195-202.

24. Dangas G, lakovou I, Nikolsky E, Aymong ED, Mintz GS, Kipshidze NN, et al. Contrast-induced nephropathy after percutaneous coronary interventions in relation to chronic kidney disease and hemodynamic variables. Am J Cardiol. 2005;95:13-9.

25. Ando G, Morabito G, de Gregorio C, Trio O, Saporito F, Oreto G. Age, glomerular filtration rate, ejection fraction, and the AGEF score predict contrast-induced nephropathy in patients with acute myocardial infarction undergoing primary percutaneous coronary intervention. Catheter Cardiovasc Interv. 2013;82:878-85.

26. Zeng JF, Chen SQ, Ye JF, Chen Y, Lei L, Liu XQ, et al. A simple risk score model for predicting contrast-induced nephropathy after coronary angiography in patients with diabetes. Clin Exp Nephrol. 2019;23:969-81.

27. Marenzi G, Lauri G, Assanelli E, Campodonico J, De Metrio M, Marana I, et al. Contrast-induced nephropathy in patients undergoing primary angioplasty for acute myocardial infarction. J Am Coll Cardiol. 2004;44:1780-5.

28. Bartholomew BA, Harjai KJ, Dukkipati S, Boura JA, Yerkey MW, Glazier S, et al. Impact of nephropathy after percutaneous coronary intervention and a method for risk stratification. Am J Cardiol. 2004;93:1515-9.

29. Ji L, Su X, Qin W, Mi X, Liu F, Tang X, et al. Novel risk score of contrastinduced nephropathy after percutaneous coronary intervention. Nephrology (Carlton). 2015;20:544-51.

30. McCullough PA, Choi JP, Feghali GA, Schussler JM, Stoler RM, Vallabahn RC, et al. Contrast-induced acute kidney injury. J Am Coll Cardiol. 2016;68:146573.

31. McCullough PA, Adam A, Becker CR, Davidson C, Lameire N, Stacul F, et al. Risk prediction of contrast-induced nephropathy. Am J Cardiol. 2006;98:27K$36 \mathrm{~K}$.

32. Koo HM, Doh FM, Ko Kl, Kim CH, Lee MJ, Oh HJ, et al. Diastolic dysfunction is associated with an increased risk of contrast-induced nephropathy: a retrospective cohort study. BMC Nephrol. 2013;14:146.

33. Sabeti S, Schillinger M, Mlekusch W, Ahmadi R, Minar E. Reduction in renal function after renal arteriography and after renal artery angioplasty. Eur J Vasc Endovasc Surg. 2002;24:156-60.

34. Rudnick MR, Goldfarb S, Wexler L, Ludbrook PA, Murphy MJ, Halpern EF et al. Nephrotoxicity of ionic and nonionic contrast media in 1196 patients: a randomized trial. The Iohexol Cooperative Study. Kidney Int. 1995;47:25461.

35. Wilhelm-Leen E, Montez-Rath ME, Chertow G. Estimating the risk of radiocontrast-associated nephropathy. J Am Soc Nephrol. 2017;28:653-9.

36. Hinson JS, Ehmann MR, Fine DM, Fishman EK, Toerper MF, Rothman RE, et al. Risk of acute kidney injury after intravenous contrast media administration. Ann Emerg Med. 2017;69:577-86.e4.

37. Hu X, Zhuang X, Li Y, Li F, Guo Y, Du Z, et al. A Nomogram to predict contrast induced nephropathy in patients undergoing percutaneous coronary intervention. Int Heart J. 2017:58:191-6.

38. Gao Y, Li D, Cheng H, Chen Y. Derivation and validation of a risk score for contrast-induced nephropathy after cardiac catheterization in Chinese patients. Clin Exp Nephrol. 2014;18:892-8.

39. Kellum JA, Lameire N, Aspelin P, Barsoum RS, Burdmann EA, Goldstein SL, et al. Kidney disease: improving global outcomes (KDIGO) acute kidney 
injury work group. KDIGO Clinical Practice Guideline for Acute Kidney Injury 2012.

40. Nagy K, Ujszaszi A, Czira ME, Remport A, Kovesdy CP, Mathe Z, et al. Association between serum resistin level and outcomes in kidney transplant recipients. Transpl Int. 2016;29:352-61.

41. Nijssen EC, Rennenberg RJ, Nelemans PJ, Essers BA, Janssen MM, Vermeeren $M A$, et al. Prophylactic hydration to protect renal function from intravascular iodinated contrast material in patients at high risk of contrast-induced nephropathy (AMACING): a prospective, randomised, phase 3, controlled, open-label, non-inferiority trial. Lancet. 2017;389:1312-22.

\section{Publisher's Note}

Springer Nature remains neutral with regard to jurisdictional claims in published maps and institutional affiliations.

Ready to submit your research? Choose BMC and benefit from:

- fast, convenient online submission

- thorough peer review by experienced researchers in your field

- rapid publication on acceptance

- support for research data, including large and complex data types

- gold Open Access which fosters wider collaboration and increased citations

- maximum visibility for your research: over $100 \mathrm{M}$ website views per year

At BMC, research is always in progress.

Learn more biomedcentral.com/submissions 